\title{
Infección urinaria en niños del Area Norte de Santiago: Aspectos clínicos y epidemiológicos
}

\author{
Rosanna Lagos $Z^{1}$; Manuel Becerra T. ${ }^{2}$; Erika Abarca M. ${ }^{3}$ \\ Medical care of children with positive urine bacterial cultures
}

\begin{abstract}
To estimate the frequency of urinary tract infections \{UTI\}, and to assess potential deficiencies in medical care of chitdren with this problem, a 6 month sample of laboratory records of a children's hospital covering 180000 inhabitants under age 15 year at Santiago, Chile, was retrospectively used as source of șuspicious cases. With the identification data of all urine specimens with $>10$ leukocytesimm ${ }^{3}$ and positive bacterial cultures $:>10^{5}$ UFC; mb), outpatient and hospital charts were localized and reviewed. In a six month period, 4906 urine specimens had beer sent to the laboratory, for microscopic and bacteriologic examination and 406 records satisfied the above mentinned criteria, corresponding to 363 "presumptive episodes of UTI". In 24 of 47 patients which were admitted to hospital by their first episode of UTI and whose charts were at hand, a second urine examination was done and the diagnosis of UTI was discarded in $13154 \%$ of them. Confirmation of UTI by a second examination was more probable when more than 100 white blood cells were described in the first specimen (10/13 vs. 1/11). Among 97 outpatients with available satisfactory charts a mean of 6 days went on between clinical suspicion of UTI and specimen reception at laboratory, and another mean 16 davs were spent from diagnosis to initial treatment. which was given to 88 of these patients. Only 31 ambulatory cared cases had follow-up bacteriolagical examinations. The low detection rates of UT, in this particular pediatric population 14.02 cases $/ 1000$ inhabitants aged 15 years or less per yearl, mav be due to failure to cover all urine specimens of patients from this health area or to low recogrition and or search of suspects.
\end{abstract}

(Key words: Urinary tract infection, diagnosis, management.)

Las infecciones del tracto urinario (ITU) son enfermedades de reconocido impacto en Salud Pública, tanto por su elevada frecuencia ${ }^{1}$, como por sus complicaciones a largo plazo ${ }^{2,3}$. Afectan a individuos de grupos etarios y estratos socioeconómicos diversos y, aparentemente, no presentan variaciones geográficas significativas.

Las comunicaciones nacionales relativas a ITU han abordado variados aspectos clínicos del problema $a^{4-7}$. En contraste con la abundancia de este tipo de publicaciones, en una revisión de la bibliografia nacional correspondiente a los 5 últimos años, encontramos sólo una publicación destjnada a analizar aspectos epidemiológicos de estas enfermedades 8 .

Exponemos los resultados de un estudio retrospectivo, cuya finalidad fue estimar la fre-

1. Unidad de Infecciosos, Hospital "Roberto del Río". Servicio de Salud Metropolitano Norte.

2. Becado. Departamento de Pediatría, Facultad de Medicina Campus Norte, Universidad de Chile.

3. Interna. Carrera de Medicina, Facultad de Medicina Campus Norte, Universidad de Chile. cuencia de las ITU en la población pediátrica beneficiaria del Servicio de Salud Metropolita. no Norte. En los pacientes sin antecedentes de ITU, documentada bacteriológicamente, nos interesó, además, detectar posibles deficiencias en la atención médica de su enfermedad.

La revisión fue realizada a partir de los libros de laboratorio del Hospital "Roberto del Rio", desde donde se extrajeron los datos de identificación de los niños que, en el periodo comprendido entre el 1 de mayo y el 31 de octubre de 1990, aparecían en esos registros con exámenes de orina que revelaron leucocituria igual o mayor de 10 elementos por $\mathrm{mm}^{3}$, y uro cultivo positivo a un germen, con recuento igual o mayor a $10^{5}$ unidades formadoras de colonias por $\mathrm{ml}$ (UFC/ml).

\section{Pacientes y Métodos}

Fuente de pesquisa / Criterio de selección: definición de estudio urinarto "sugerente de ITU"

Dado que el Hospital "Roberto del Río" atiende las demandas de exámenes de todos los niños bene- 
ficiarios del Servicio de Salud Metropolitano Vinte y que sólo una minoría de esta población está adscrita a otros sistemas de atención en salud, se utjlizaron los registros del laboratorio de dicho hospital pata pesquisar los episodios de ITU ocurridos en esta comunidad, en el período comprendido entre el 1 de mayo y el 31 de octubre de 1990.

Se consideraron "sugerentes de ITU" los estudios urinarios que revelaron leucocituria mayor o igual a 10 elementos por $\mathrm{mm}^{3}$ (en muestra de orina no centrifugada), con cultivo positivo a un solo germen, con recuento igual o superior a $10^{s} \mathrm{UFC} / \mathrm{ml}$.

Todos los registros que cumplieron la definicion antcs señalada fueron incorporados a un listado inicial, que incluyó adentás la fecha de obtención, el origen de la solicitud y la identificación de la muestra. T:n base a estos datos se procedió a localizar las fichas cínicas currespondientes.

\section{Revisión de fichas clinicos f Criterios de exchsión}

Los registros incorporados al listado provenían de tres distintos niveles de atención: servicio de urgencias, unidades Clínicas del Hospital "Roberto del Río", consultorios adosados de especial datades y consultorios periféricos del Area Norte de Salud. El protocolo de revisión aplicado fue diferente según el nivel de batención que originó la solicitud del estudio urinario: en los casas en que ésta fue emitida desde alguna de las unidades de hospitalización. la revisión de las fichas consideró tos siguientes aspectos: motino de la sospecha de ITU, repetición del estudio urinario (previo al inicio del tratamiento), enfermedades concomitantes, hemograma, velocidad de eritrosedimentación (VHS), Proteína C ractiva (PCR), hemocultivos, control bacteriológico dutante el tratamiento y seguimiento en el consultorio de nefrourología.

Los antecedentes de los pacientes con solicitud proveniente de algu no de los 14 consultorios periféricos fueron investigados visitando cada uno de estos centros; cn las fichas correspondientes se buscó la fecha y el motivo de la solicitud del estudio urinario, los sintomas registrados en la consuita, la fecha de inicio del tratamiente, el medicamento indicado y el resultado de] control bacteriológico posterior al tratamiento. Además se averiguó la existencia de una ficha en el hospital y se buscó registros de consuitas a nefrourología.

En los pacientes atendidos en el servicin de urgencias, sólo se indagó la existencia de una ficha hospitalaria y, cuando la hubo, se procedió como en el caso anterior.

Toda vez que el número de ficha no cstaba anotado en el libro del laboratorio o cuando ésta no coincidió con los demás datos de identificación, se realizó una búsqueda en el registro alfabético del establecimiento. En todos los casos se agotaron los medios para localizar las fichas extraviadas.

Fueron exchuidos del análisis los registros cuyos datos de jdentificación (nombre y apellidos) fueron insuficientes para investigar, al menos, la existencia de una ticha hospitalaria y los pertenecientes a pacientes que fallecieron durante la hospitulización por causas no rciacionadas con ITU.

Dado que la calidad de los registros clínicos disponibles fue variable $y$ que, en rigor, sólo una minoría de los pacientes cumplió con las exigencias actuales para el diagnóstico de [TU": ${ }^{10}$. nos referiromos a "primeros episodios sospechosos de ITU", aludiendo a los casos en que la revisión de la ficha ambulatoria, la bospitalaria o ambas, no teveló la existencia de un episodio previo, bacteriológicamente documentado. Por el contrario, los casos con eviuencias bacteriológicas de ITU anteriores fueron eatalogados como "recurrencias". In los pacientes con más de un registro los exámenes separados entre sj́ por un lapso menor de 15 días fueron atribuidos a un misno episodio "suspechoso de ITU". La localización de las ITU fiue deducida de los datos registrados en las historias, aplicando los criterios clínicos y de laboratorio clásicamente usadus para diferenciar las infecciones altas de las bajas", 1t.

La jnformación recopilada en la revisión de fïchas fue almacenada en tres bases de datos, una para cada protocolo de revisión. y procesada en un microcompu. tador. Para el análisis estad istico se realizaron cálculos de diferencias de proporciones, chi-cuadrado y pruebas de "t". El valor de significación fue fijado en valores de $\mathrm{p}<0,05$.

\section{Resultados}

En el periudo de seis meses abarcado por esta revision, el laboratorio del Hospital "Roberto del Rio" procesó 4906 muestras de arina, con solicitud de estudio microscópico y bacteriológico simultáneos. En $406(8,3 \%)$ se encontró leucocituria igual o mayor de 10 elementos por $\mathrm{mm}^{3}$, y cultivo positivo a un germen, en secuento igual o superior a $10^{5}$ UFC/nil. Las muestras con estas características pertenecian a 336 niños, que presentaron 363 "episodios sospechosos de ITU"; para la población infantil del Area Norte, esto representaria una inciden. cia de 1,8/1000 menores de 15 años, enl el semestre estudiado $(3,6 / 1000$ anual). Doscientos setenta $y$ siete episodios (76\%) ocurrieron en pacientes de sexo femenino; sin embargo, en el grupo de menores de un año, los varones predominaron sobre las niñas en relación de $1,4: 1$.

Pacientes hospitalizados: Ciento quince de lus registros incorporados al listado inicial pertenecían a 69 pacientes hospitalizados, los cuales presentaron 72 "episodios sospechosos de ITU". Entre ellos, 39 registros fueron excluidos del análisis $(34 \%)$ : 16 pertenecian a 7 pacientes fallecidos durante la hospitalización, por causas no atribuibles a ITU; en 3 casos no fue posible localizar las fichas clínicas cotrespondientes y 20 registros pertenecían a niños con ITL y enfermedades nefrourológicas previamente diagnosticadas. Los 76 registros restantes correspon. dían a 47 enfermos en el momento de su "primer episodio de sospecha de ITU". La mayoría 
de los menores de 1 año eran varones ( 16 de 2 ), $71,4 \%$ ), mientras que las niñas predominaron en las demás categorías etarias.

En el momento de la solicitud del examen, 25 de los 47 pacientes presentaba alguna enfermedad infecciosa concomitante (síndrome diarreico agudo con aislamiento de enteropatógenos 0 intolerancia a hidratos de carbono o ambos en 6 casos; bronconeumonía con documentación radiológica en 18 casos y síndrome coqueluchoideo en un caso). En los otros 22, el estudio urinario "sugerente de ITU" se presentó en ausencia de otros focos infecciosos. Los grupos antes mencionados (con y sin enfermedades asociadas), difirieron significativamente en su composición etaria (tabla 1), en la magnitud de la leucocituria y en la proporción de casos con recuento de glóbulos blancos igual o mayor a 100 por $\mathrm{mm}^{3}$ (tabla 2). En la mitad de los casos de ambos grupos (24 de 47), los médicos tratantes indicaron repetir el estudio urinario antes de adoptar una conducta terapéutica. En ellos, la proporción de segundas muestras con resultado bacteriológico igual al inicial fue significativamente mayor en los pacientes sin afecciones asociadas (10 de 11), que en los que presentaban alguna otra enfermedad infecciosa ( 2 de 13 ). Por otra parte, la confirmación del primer urocultivo estuvo estrechamente asociada a la magnitud de la leucocituria: los cultivos de 11 de 13 muestras con leucocituria mayor de 100 elementos por $\mathrm{mm}^{3}$ fueron corroborados por la segunda muestra, mientras que, en sólo uno
Tabla 1

Distribucjón etaria de 47 pacientes hospjtalarjos con estudio urinario "sugesente de ITU": Comparación según presencia o ausencia de enfermedades asociadas

\begin{tabular}{lcc}
\hline & $\begin{array}{c}\text { Con infecciones } \\
\text { asociadas } \\
(\mathrm{n}: 25)\end{array}$ & $\begin{array}{c}\text { Sin infecciones } \\
\text { asociadas } \\
\text { (n: 22) }\end{array}$ \\
\hline EDADES & $5 \mathrm{~m}$ & 1 a $5 \mathrm{~m}$ \\
Mediana & 13 & 8 \\
1 a & 11 & 6 \\
$1<5 \mathrm{a}$ & 1 & 8 \\
$75 \mathrm{a}$ &
\end{tabular}

de 11 casos de leucocituria menor de 100 por $\mathrm{mm}^{3}$, ambos cultivos tuvieron igual resultado (tabla 2). El estudio del nivel anatómico de la infección, mediante los parámetros de fase aguda de la inflamación, no fue practicado en forma sistemática en ninguno de estos dos grupos; pese a que los niños $\sin$ afecciones asociadas mostraron mayor tendencia a presentar leucocitosis y desviación a la izquierda, esta muestra sólo permitió demostrar diferencias significativas en la velocidad de eritrosedimentación (promedios $=21 \mathrm{~mm} / \mathrm{h}$ vs. $61 \mathrm{~mm} / \mathrm{h} ; \mathbf{t}=3,8 ; \mathrm{p}=$ $0,001)$. La frecuencia de aislamiento de $E$. coli (en orina) fue similar en ambos grupos, aunque ligeramente mayor entre los nifios sin enferme. dades concomitantes ( 80 vs. $72 \%$ ). En 12 de es-

Tabla 2

\begin{abstract}
Comportamiento de la leucocituria en $\mathbf{4 7}$ pacientes hospitalarios con estudio urinario
"sugerente de ITU", según presencia o ausencia de enfermedades asociadas al momento de la sospecha
\end{abstract}

\begin{tabular}{|c|c|c|c|}
\hline & $\begin{array}{c}\text { Con infecciones } \\
\text { asociadas } \\
\text { (n: } 25)\end{array}$ & $\begin{array}{c}\text { Sín infecciones } \\
\text { asociadas } \\
\text { (n: 22) }\end{array}$ & \\
\hline \multicolumn{4}{|l|}{ Leucocituria I ${ }^{2}$ muestra } \\
\hline $\begin{array}{l}\text { Mediana }\left(x \mathrm{~mm}^{3}\right) \\
\% \operatorname{con}+\text { de } 100 \times \mathrm{mm}^{3}\end{array}$ & $\begin{array}{l}40 \\
40\end{array}$ & $\begin{array}{r}930 \\
80\end{array}$ & $\begin{array}{l}t=-2,7 ; P=0,008 \\
z=2,48 ; P=0,013\end{array}$ \\
\hline \multicolumn{4}{|l|}{ Leucocituria $2^{2}$ muestra } \\
\hline $\begin{array}{l}N \text { con } 2 \text { muestras } \\
\text { Mediana }\left(x \mathrm{~mm}^{3}\right) \\
\% \text { con }+ \text { de } 100 \times \mathrm{mm}^{3}\end{array}$ & $\begin{array}{c}13 \\
4 \\
7,7\end{array}$ & $\begin{array}{c}11 \\
1400 \\
81,8\end{array}$ & $\begin{array}{l}\mathrm{t}=-2, \mathbf{1} ; p=0,05 \\
\mathrm{z}=3,25 ; \mathrm{p}=0,001\end{array}$ \\
\hline Casos confürmados $\operatorname{con} 2^{\mathrm{a}}$ muestra & 2 & 10 & $z=3,25 ; P=0,001$ \\
\hline
\end{tabular}


tos últimos pacientes se indicó hemocultivos, 7 de los cuales resultaron positivos para $E$. coli. La presencia de bacteremia fue investigada en sólo un niño del grupo con infecciones asociadas; en este caso, el resultado del estudio fue negativo.

Veintinueve de los 47 episodios "sospechosos de ITU" recibieron tratamiento antimicrobiano; de ellos, 21 presentaban signos clínicos o de laboratorio compatibles con pielonefritis aguda. En 12 episodios la sospecha de ITC fue descartada con el segundo examen de orina $y$, en 6 casos, los hallazgos urinarios fueron desestimados. En todos los pacientes tratados se prac. ticó, al menos, un control bacteriológico de orina durante la hospitalización.

Pacientes ambulatorios: Las solicitudes de 101 exámenes procedían del consultorio adosado de nefrourología; de acuerdo a la revisión de las correspondientes fichas clínicas, estos estudios fueron clasificados como sigue: 88 episodios de recurrencias, en 67 pacientes portadores de patología nefrourológica conocida (1,3 episodios por paciente); 4 episodios no anatizados por extravio de la ficha clínica y 9 primeros episodios de ITU sintomática. Los pacientes con infecciones recurrentes eran, predominantemente, de sexo femenino ( 49 de $67,73,1 \%$ ), en tanto que 5 de los 9 "primeros episodios" ocurrieron en varones. El diagnóstico fue pielonefritis aguda, en 5 de estos 9 casos.

La unidad de emergencias aportó 74 estudios "sugerentes de ITU", solicitados a igual número de pacientes. Este grupo estuvo constituido mayoritariamente por nifas $(85 \%)$. En estos enfer- mos no se investigó el motivo de la solicitud del estudio, ni el manejo terapéutico del cuadro. La revisión del registro alfabético del hospital abarcó 72 de los 74 pacientes y fue impracticable en 2 , cuyos datos de identificación eran incompletos: 34 niños no figuraban en el fichero y otros 30 , que tenfan fichas, no registraban consultas en Nefrourología. Ocho acudieron a ese consultorio después de la atención en la posta, tres de los cuales tenían atenciones por ITU previas.

Ciento die $z$ registros "sugerentes de ITU" pertenecian a igual número de pacientes, atendidos en los 14 consultorios periféricos del Area Norte y otros 6 procedían de consultorios de especialidades adosados al hospital, diferentes de nefrourologia. De acuerdo a la población infantil asignada a cada uno de los policlínicos periféricos, las tasas de estudjos urinarios "sospechosos de ITU" variaron en un rango de 0,18 a $1,6 / 1000$ menores de 15 años.

Los pacientes con "primeros episodios de sospecha de ITU" atendidos en el consultorio de nefrourologia tenían distribución etaria similar a la de los niños hospitalizados (mediana de 1 año 3 meses en ambos grupos). En cambjo, las medianas etarias de los nirnos atendidos en la Unidad de Emergencias (6 años), y la de los casos detectados en los consultorios periféricos (6 años), fueron similares a la de los niños con "recurrencias" (5 años 6 meses). La magnitud de la leucocituria $y$ la frecuencia de aislamiento de $E$. coli, de cada uno de los grupos de pacientes ambulatorios y de los niños que recibieron tratamiento en el hospital se muestran en la tabla 3 .

Tabla 3

Comportamiento de la leucocituria y frecuencia de aislamientos de $E$. coli en 198 primeros episodios de "sospecha de ITU" y en 111 "recurrencias"

\begin{tabular}{|c|c|c|c|c|}
\hline & \multicolumn{4}{|c|}{ LEUCOCITURIA } \\
\hline & $\pi$ Casos & Promedio & $\alpha>100$ & $\%$ E. coli \\
\hline Consultorio de nefrourolog ia & 9 & 829 & 88,8 & $\mathbf{8 8 , 8}$ \\
\hline Unidad de emergencia & 69 & 2359 & 85,5 & 97,1 \\
\hline Consultorios periféricos & 91 & 1796 & 72,5 & 96,7 \\
\hline Hospital & 29 & 2253 & 86,2 & 89,6 \\
\hline Recurrencias & 111 & 1231 & 72,0 & 73,8 \\
\hline
\end{tabular}

Se incluyen sólo los registros con datos de identificación suficientes para buscar, al menos, la ficha clínica del hospital, 
La siguiente descripción comprende $97 \mathrm{pa}$ :ientes con estudio urinario "sospechoso de IT'U", en los que fue posible localizar la ficha slínica de atención ambulatoria:

En seis de las fichas clínicas se encontró rejistros de ITU previas, bacteriológicamente dozumentadas. La fecha de solicitud del estudio urinario estaba consignada en $9 \mathrm{~J}$ de las $97 \mathrm{fi}$ chas disponibles; en promedio, el lapso transcurrido entre esta fecha y la de recepción de la muestra en el laboratorio fue de 6 dias (rango de 1 a 56 dias, y mediana de 3 dias). El motivo de la solicitud del estudio urinario estaba registrado en 91 de las fichas: en 49 casos habia síntomas, signos o ambos, compatibles con pielonefritis; en 33 fichas el cuadro descrito era sugerente de ITU baja y 9 fueron estudios practicados a pacientes con mal incremento ponderal o enuresis. En 6 casos no se registró los motivos de sospecha de ITU. La fecha de inicio del tratamiento estaba registrada, o pudo ser inferida, en 89 de las 97 fichas analizadas: en 18 casos se indicó iniciar el tratamiento inmediatamente después de obtenidas las muestras para exámenes. En 79 casos el tratamiento fue diferido, en espera de los resultados de los exámenes de orina; 8 de estos pacientes no regresaron a control, en tanto que, en los 71 restantes, el inicio del tratamiento se indicó, en promedio, 10 dias después de la toma de muestra (16 dias después de la primera consulta; mediana $=3$ y rango de 2 a 72 dias). Se prescribió nitrofurantóna en 68 de los $88(77 \%)$ pacientes que recibieron in. dicaciones terapéuticas, incluyendo $35(71,4 \%)$ de los casos compatibles con pielonefritis. Tres pacientes fueron derivados para hospitalizacion; dos de ellos, habiendo iniciado su tratamiento con nitrofurantoína, presentaron intolerancia al medicamento y deterioro de su condición clínica. Los demás niños con signos de infección alta recibieron: gentamicina seguida de un medicamento por wía oral ( 3 casos) y co. trimoxa\%ol (8 pacientes, con fracaso del trata. miento documentado en 2 casos); en otros 2 pacientes no habia registros de atención médica posterior a la que motivó el estudio urinario.

En 31 de los 89 pacientes tratados se practicó un control bacteriológico post-tratamiento.

En la búsqueda de registros hospitalarios (de los 91 niños sin antecedentes de ITU) encontranios 44 niños sin ficha en el hospital. De los 47 restantes (con ficha hospitalaria), 18 registraban consultas a Nefrourología.
Seguimiento de pacientes sin antecedentes de ITU. Los 29 niños tratados en el hospital fueron dados de alta con indicación de concurrir al policlínico adosado de Nefrourologia, para estudio y seguimiento. En el momento de la presente revisión (marzo de 1991), 9 pacientes asis. tían regulamente a controles y 20 habian abandonado el seguimiento. En los 9 pacientes cuyo primer episodio de ITU fue atendido en el consultotio de nefrourología se indicó exámenes de orina post-tratamiento, ecografía renal, uretrocistografía miccional y control. El cumplimiento de estas indicaciones fue nulo en 5 de los niños, mientras que los otros 4 asisten adecuadamente a sus citaciones. De los cinco enfermos procedentes del servicio de urgencia, 3 han continuado en control y 2 no regresaron después de la primera consulta. De los 91 niños con "primer episodio de ITU" atendidos en policlínicos periféricos, 18 consultaron en nefrourología: 9 abandonaron el seguimiento después de la primera consulta y los otros 9 habían asistido regularmente a sus citaciones, hasta marzo de 1991.

En suma, 57 de 198 pacientes con "presunto primer episodio de ITU" fueron atendidos en el consultorio de la especialidad: de ellos, 29 abandonaron el seguimiento después de la primera consulta, sin practicarse estudios y 2 lo hicieron después de haberse realizado ecografía y uretrocistografía miccional sériada (CUMS), que resultaron nomrales. Otros 26 enfermos han continuado en seguimiento: 4 tienen estudio ecográfico normal y no han tenido recurrencias; 16 tienen ecografia y CUMS nomales, 3 de los cuales han presentado recurrencias de ITU; en 5 pacientes se ha demostrado reflujo vesicoureteral (RVU): 3 de ellos tienen, además, una cicatriz renal. Por último, en un paciente se detectó un doble sistema pielocaliciario.

\section{Comentario}

El trabajo expuesto representa, según nuestro conocimiento, el primer intento por estimar la frecuencia de las ITU en la población pediátrica beneficiaria del Servicio de Salud Metropolitano Norte, y de detectar problemas relacionados con la atención médica de los pacientes con estas patologías.

De acuerdo a los datos recopilados, la tasa anual de ITU en esta comunidad sería del orden 
de 4,02/1000 menores de 15 años, cifra muy inferior a las comunicadas en publicaciones extranjeras $1,2,10$. Lejos de sugerir una situación privilegiada de nuestra población, estimamos que esta diferencia refleja las limitaciones de la metodologia aplicada, que, en primer lugar, no permitió cuantificar ni analizar los casos de ITU tratados sin estudio de laboratorio, ni los que pudieron acceder a sistemas de atención privada; en segundo lugar, el criterio de selección de casos sospechosos, basado exclusivamente en elementos de laboratorio, pudo haber excluido "falsos negativos", que no reunieron los requisitos predefinidos. Por otra parte, la reducida proporción de pacientes ambulatorios menores de un año sugiere un bajo indice de sospecha de estas infecciones en este grupo etario. Por lo mismo, es posible que algunos de los "primeros episodios" aqui descritos correspondan, en realidad, a recurrencias, en niños cuya primera ITU no fue diagnosticada (asi lo sugiere, tam. bién, la similitud de la distribución etaria de los pacientes con prestintos "primeros episodios" atendidos en forma ambulatoria, respecto a la de los pacientes con recurrencias). Aunque nos es imposible objetivar la magnitud de la distorsión condicionada por estos factores, es de suponer que todos ellos actuaran en el sentido de disminuir la magnitud real del problema.

En los casos en que fue posible conocer datos clínicos relativos al episodio se encontró que más de la mitad de los pacientes sin antecedentes de afección nefrourológica tuvo signos compa. tibles con pielonefritis aguda. Asi, extrapolando la experiencia comunicada por Winberg ${ }^{3}$, la serie de niños aquí descrita daría origen, al menos, a 2 pacientes hipertensos, 2 que requerirán una nefrectomía y un insuficiente renal terminal, además de I a 2 mujeres con toxemia del embarazo. La magnitud de estas consecuencias debe ser ponderada considerando también lo expuesto en el párrafo arterior.

Aunque minoritarios en esta serie, los pacientes hospitalizados presentaron ciertas particularidades que merecen atención. Entre estos niños se detectaron dos factores que incidieron en aumentar la complejidad del diagnóstico de las ITU: primero, una elevada proporción de pacientes menores de I año, grupo etario característicamente asociado con manifestaciones inespecíficas de la enfermedad ${ }^{12}: y$ segundo, la sospecha de ITU en frecuente concomitancia con otros cuadros infecciosos, potencialmente capaces de interferir en la interpretación de los elementos usados para estimar el nivel anatómico de la infección. Por otra parte, es llamativo que, aún en presencia de estas otras enfermedades, los parámetros de laboratorio sugerian un predominio de infecciones hajas en ese grupo de pacientes. Consistente con lo anterior, la repetición de los exámenes de orina permitió descartar la existencia de ITL en la mayoría de los pacientes en que se optó por confirmar el diagnóstico con un segundo estudio. Por último, nos parece destacable la proporción de casos con aislamiento del agente patógeno en sangre. Aunque la literatura no aporta datos precisos al respecto, se señala que los hemocultivos son positivos más frecuentemente en los niños menores de un mes $^{10}$. Dado que esta condición estuvo presente sólo en uno de nuestros enfermos con bacteremia, y que el significado pronóstico de ella es desconocido, parece aconsejable instituir la práctica sistemática de hemocuitivos en todos Ios pacientes con sospecha de pielonefritis.

Estimamos que las observaciones antes descritas indican la necesidad de mejorar la acuciosidad de los diagnósticos de ITU en el ambiente hospitalario y de disponer de recursos de apoyo diagnóstico que permitan evaluar el nivel ana. tómico de la infección, obviando la potencial interferencia de afecciones concomitantes. Ambas medidas contribuirían a reducir los tratamientos innecesarios y la demanda injustificada de estudios por imágenes y de atención médica especializada.

Los episodios sospechosos de $1 \mathrm{TC}$ atendjos en forma ambulatoria dejaron en evidencia deficiencias alamantes en todas las etapas de su manejo médico: retardo en el diagnóstico de laboratorio, inicio tardío del tratamiento, ausencia de estudios destinados a precisar la localización de la infección, elección inadecuada de antimicrobianos e infrecuente control bacterio. lógico post-tratamiento; a todo lo anterior se agregó una escasa demanda de atentión especializada y un peor cumplimiento del seguimiento en el consultorio de nefrourologia. A nuestro juicio, las deficiencias antes mencionadas se originan, fundamentalmente, en dificultades para el acceso de los pacientes a los estudios de laboratorio, y a desinformación por parte de toda la comunidad, respecto de la importancia de estas enfermedades.

En la actualidad se recomienda que el diag. nóstico de ITU se fundamente en los resultados 
de dos urocultivos (o en uno obtenido por aspiración vesical $)^{9,10}$. Aunque ninguno de los pacientes ambulatorios de esta serie cumplío con esta exigencia, nuestra impresión es que la pro. porción de falsos positivos debería ser despre. ciable: en primer lugar, la edad de los niños, y lo registrado en las fichas clinicas apuntan a que la mayoría de estos enfermos consultó refiriendo sintomas de ITU. Por otra parte, Ja cuantía de la leucocituria fue sugerente de que la bacteriuria se acompañó de un intenso componente inflamatorio. Aunque la validez de este elemento en el diagnóstico de ITU ha sido motivo de largas controversias, nuestras observaciones en los pacientes hospitalizados coinciden con las experiencias comunicadas por otros autores ${ }^{13,14}$. De acuerdo a nuestros datos, el hallazgo de bacteriuria significativa, asociado a la presencia de 100 o más leucocitos por $\mathrm{mm}^{3}$, tuvo una eficiencia de $87 \%$ para predecir la confirmación del diagnóstico de ITU (con la segunda muestra), con valores predictivos positivo y negativo de 84,6 y $90,9 \%$, respectivamente. Dadas las dificultades actuales para el estudio ambulatorio de las ITU, estimamos que el examen microscópico de onina debe ser considerado de gran ayuda en la interpretación del resultado de un estudio bacteriológico aislado. Una evaluación más directa del rendimiento del urocultivo, en función de la leucocituria, es objeto de un estudio actualmente en curso.

Este trabajo entrega una visión subestimada, y por ello doblemente alarmante, de un problema cuyo impacto en sajud pública no ha sido evaluado en nuestro país, y cuyas consecuen. cias son claramente deducibles de la experiencia extranjera.

Las deficiencias detectadas en el manejo de los pacientes con sospecha de ITU son variadas, y su corrección requiere de acciones coordinadas en todos los niveles de la atención en salud: educación masiva de la comunidad, mejoramiento de los recursos diagnósticos y terapéuticos en la práctica ambulatoria, e implementación de tecnologia adecuada para el estudio y manejo de pacientes complejos en el medio hospitalario. Lo anterior exigira, sin duda, un esfuerzo considerable de todos los sectores involucrados; sin embargo, en el estado actual de desarrollo de la salud en nuestro país, es inipostergable asumir y abordar a cabalidad la problemática de las ITU (y de otras enfermedades de complejidad similar) a fin de mantener la tendencia actual en la evolución de los índices de salud de la población.

\section{Resumen}

Con el propósito de estimar la frecuencia de las ITU en la población peđiátrica del Area Norte y evaluar la calidad de la atención médica otorgada a tales pacientes, se revisaron las fichas clinicas hospitalarias y ambulatorias de los nifos que, entre mayo y octubre de 1990, aparecian en los registros de laboratorio de un hospital metropolitano de Santiago que atiende a una población de 180000 niños de 15 o menos años de edad, con leucocituria $\geqslant 10$ elementos por $\mathrm{mm}^{3}$ y cultivo puro, con recuento $\geqslant 10^{5}$ UFC/ $\mathrm{ml}$, en la misma muestra de orina. Cuatrocientos seis de 4906 registros reunieron las condiciones antes señaladas, los cuales correspondieron a 363 "episodjos sospechosos" de ITU; esta cifra representa una tasa anual de $4,02 / 1000$. Se analizaron en detalle 47 fichas hospitalarias y 91 de consultorios periféricos, correspondientes a pacientes sin antecedentes de ITU. En 24 de los pacjentes hospitalizados se indicó un segundo examen de orina antes del inicio del tratamiento, la mitad de los cuales permitió descartar la sospecha de ITU; en estos casos (con 2 exámenes de orina), ta presencia de leucocituria $\geqslant 100$ elementos por $\mathrm{mm}^{3}$, permitió predecir la confirmación del diagnóstico con una eficiencia de $87 \%$ (11/13 vs. 1/11). Entre los pacientes ambulato. rios, el lapso entre la sospecha de ITU y la recepción de la muestra en el laboratorio fue, en promedio, de seis dias; en 71 casos transcurrieron, en promedio, 16 días antes del inicio del tratamiento y sólo 31 pacientes tuvieron un control bacteriológico posterior. En conjunto, sólo $13 \%$ de los pacientes con primer episodio de sospecha de ITU analizados en esta serie ha cumplido adecuadamente su seguimiento, en el consultorio de nefrou rología.

(Palabras claves: Infección urinaria, diagnòstico, manejo).

\section{Agradecimientos}

Los autores agradecen a tos doctores Isidoro Horwitz y Gastón Duffau, por su valiosa lectura crítica del manuscrita y al Dr. Patricio Herrera, por sa ayuda en el análisis estadístico. 


\section{Referencias}

1. Winberg $f$, Andersen $H$, Bersgrom $T$, Jacobson $B$,

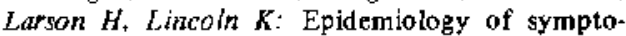
matic urinary tract infections in chilhood. Acta Paediatr Scand 1974: Suppl. 252.

2. Guillenwater JY, Larrison RB, Kunin CM: Natural History of Bacteriuria in Schoolgirls. N Engl J Med $1979 ; 301: 396-399$.

3. Winberg $J$, Jakobsson B, Eklof $O$ et al.: Development of hipertension and uremia following childhood pyelonephritis. 30 years follow up. Abstract 4005: VIII Congress of the International Pediatric Nephrology Association. Toronto, AugustSept. 1989.

4. Gasc OO, Mitnik M, Gase LO, González A: Tratamiento abreviado de la infección del tracto urina$r$ ío en niños. Pediatr ía $1985 ; 28: 94-96$.

5. Weinberger $M$, Durruty $P$, Gorcia de los Rios $M$, Forias $O$, Pinto $M E$ : Niveles séricos de complemento C3-C4 en diabéticos no insulinodependientes y su relación con la infección urinaria. Boletín del Hospital San Juan de Dios 1986; 33: 392-395.

6. Bogado $J$, Hidalgo $F$ : Cistitis intersticial: Diagnóstico y tratamiento. Revista Chilena de Urologia $1986 ; 49: 34-37$.

7. Yunge $P$, MacMillan $S$, Mackillan $N$; Rendimiento del estudio radiológico en nuiños con infección uri- naria. Revista Chilena de Urologia 1986; 49 \$8-61.

8. Inzuiza GM, De la Torre FN, Honke CM: Evaluación de un programa de seguimiento de niños con infección del tracto urinario. Bolet ín Médico del Cobre 1988; $1: 23-26$.

9. Morgileth $A M$. Pedreira FA, Hirshman GH. Cole. mon TH: Urinary tract infections. Office diagnosis and management. Pediatt Clin North Am 1976; 23: 721.733 .

10. Sobel $D D$, Kaye $D$ : Utinary Tract Infections. In: Principles and Practice of Infectious Diseases. III Edition. New York, Edimburg, London. Melbourne: Churchill Livingstone. 1990; pp. 586 611.

11. Sheldon CA, Gonzales R: Differentiation of upper and lower urinary tract infections: How and when? Med Clin North Am 1984; 68 ; 321-333.

12. Jodal $U$, Winberg $J$ : Management of children unobstructed urinary tract infection. Pediatr Nephrol $1987 ; 1: 647-656$.

13. Pylkkanen $d$, Vilska $J$, Koskimies $O$ : The value of level diagnosis of childhood urinary tract infection in predicting renal injury. Acta Paediatr Scand $1981 ; 70: 879-883$.

14. Tobaldi $R$, Giorgi $P L$ : Pyuria and its relationship with bacteriuria. Abstract 21.014: Vlil Congress of the International Pediatric Nephrology Association. Toronto, August-Sept. 1989. 